\title{
OS CONTORNOS DA RESISTÊNCIA: AGRICULTURA CAMPONESA FAMILIAR NO LIMITE DA EXPANSÃO DO MONOCULTIVO DE EUCALIPTO NO TERRITÓRIO RURAL DO BOLSÃO/MS'
}

\author{
THE OUTLINES OF THE RESISTANCE: FAMILIAR PEASANTRY \\ AGRICULTURE IN THE EXPANSION BOUNDARIES OF THE \\ EUCALYPTUS MONOCULTURE IN THE RURAL TERRITORY \\ OF BOLSÃO/MS
}

\author{
Mariele de Oliveira Silva \\ Doutoranda em Geografia na UEL \\ mosgeolice@gmail.com
}

\author{
Rosemeire Aparecida de Almeida \\ Professora Doutora em Geografia na UFMS \\ rosimeire-aparecida@uol.com.br
}

\section{Resumo}

A atual mobilidade do agronegócio do eucalipto tem ocasionado profundas transformações territoriais e ambientais no Território Rural do Bolsão/MS, em especial nas áreas de reforma agrária circunvizinhas às indústrias Fibria e Eldorado Brasil. Nessa perspectiva, objetivamos com esta pesquisa: aprender as relações de reprodução camponesa frente a expansão do complexo de Eucalipto/Celulose/Papel, junto às famílias assentadas em dois municípios do Território Rural do Bolsão/MS, a saber: Três Lagoas e Selvíria. Como metodologia de análise: revisão bibliográfica; ao uso de fontes orais; aplicação de entrevistas aleatórias. Não há dúvidas que a implantação das indústrias de celulose e papel, materializada nos municípios de Três Lagoas e Selvíria/MS, por meio da expansão da agricultura empresarial, tem provocado nova reorganização do território, e exigindo novas articulações da agricultura camponesa familiar para permanecer na terra. Dentre as novas articulações camponesas que destacam-se no Território Rural do Bolsão/MS, especialmente no que diz respeito a comercialização da produção, podemos citar a participação de grande parte dos camponeses assentados nas feiras locais e nos mercados institucionais PAA e PNAE. Fatores, que mesmo ante á política de Governo altamente comprometida com a expansão do Complexo Eucalipto/Celulose/Papel, tem permitido a recriação camponesa nesse Território.

Palavras-chave: Reorganização territorial. Complexo de Eucalipto/Celulose/Papel. Transformações territoriais e ambientais. Reprodução camponesa. Três Lagoas e Selvíria/MS.

\section{Abstract}

The current mobility of the eucalyptus agribusiness has caused deep territorial and environmental transformations in the Território Rural do Bolsão/MS, especially in the 
areas of agrarian reform that surrounds Fibria and Eldorado Brazil companies. From this perspective, we aim with this research: learn the relations of peasant reproduction in relation to the expansion of the Eucalyptus/Cellulose/Paper complex, together with families settled in two municipalities of the Território Rural do Bolsão/MS, namely: Três Lagoas and Selvíria. As analysis methodology: literature review; the use of oral sources; application of random interviews. There is no doubt that the implementation of cellulose and paper companies, materialized in the municipalities of Três Lagoas and Selvíria/MS, through the expansion of commercial agriculture, has caused a further reorganization of the territory and demanded new articulations of peasant family agriculture to remain on the land. Among the new peasant joints that stand out in the Território Rural do Bolsão/MS, especially regarding the commercialization of the production, we can mention the participation of great part of settled peasants at local fairs and also in the institutional markets PAA and PNAE. Factors that even with the highly committed government policy with the expansion of Eucalyptus/Cellulose/Paper Complex, has allowed the peasant recreation in this Territory.

Keywords: Territorial reorganization. Eucalyptus/Cellulose/Paper Complex. Territorial and environmental transformations. Peasant Reproduction. Três Lagoas and Selvíria/MS.

\section{Introdução}

A questão da insegurança fundiária representada pelas terras devolutas e improdutivas em mãos de particulares, bem como a dificuldade de demarcação das terras indígenas e quilombolas é situação historicamente ignorada pelo Estado de Mato Grosso do Sul. Neste além do descaso, há ainda o apoio as novas dinâmicas no campo, em que o latifúndio da pecuária vai cedendo espaço para as atividades de monocultivo. Exemplo é o apoio irrestrito a expansão do monocultivo de eucalipto a região que compreende o Território Rural do Bolsão/MS intensificado a partir de 2016.

Caracterizada por alguns autores como região de alta concentração fundiária, o Bolsão presencia atualmente nova reconcentração sob a égide do "grande" capital industrial, representado pela expansão territorial do monocultivo do eucalipto. Tal expansão decorre, especialmente, da escolha dos municípios de Três Lagoas e Selvíria para ser sede das duas maiores indústrias de celulose e papel do Brasil: Horizonte - controlada pela Fibria (resultante da fusão da Votorantim-celulose e papel e da Aracruz), e a outra indústria, representada pelo grupo JBS e MCL Empreendimentos, a Eldorado Brasil.

Cabe destacar que no Bolsão tem desenvolvido nos últimos anos grande entrave a desapropriação de novas áreas para a realização da Reforma Agrária. Situação decorrente da roupagem moderna do capital agroindustrial, representado pelo monocultivo de 
eucalipto sobre terras antes destinadas a pecuária extensiva, reforçando uma realidade existente na maioria dos estados brasileiros, que é a aliança entre latifundiários pecuaristas e empresários.

Acreditamos que, a apropriação privada da terra por meio dessa aliança é estratégia encontrada pelos latifundiários para encobrir terras improdutivas já em processo de desapropriação, que poderiam ser direcionadas para a política de reforma agrária. Porém, ações comuns de venda, arrendamento ou parceria realizadas para o monocultivo de eucalipto, e também de outras culturas como soja, cana, algodão, faz com que as mesmas terras, que antes eram improdutivas, se tornem produtivas e impassíveis de desapropriação.

No Bolsão, concomitantemente à instalação das fábricas, as regiões circunvizinhas aos municípios tornaram-se prioritárias para expansão do monocultivo de eucalipto, cercando tanto os projetos de assentamentos - PAs implantados em Selvíria (Alecrim, São Joaquim, Canoas I e II) quanto em Três Lagoas (Pontal do Faia e Vinte de Março).

É nítido que a ocasião desafia-nos a entender se as formas encontradas pelos assentados para manterem-se na terra, ante ao cenário de deficiência das políticas públicas do Estado, em especial, para os projetos de reforma agrária, direcionam lhes para o conformismo ou para a emancipação; ou se ambas se entrelaçam numa ambiguidade própria destas condições de reprodução em situação de bloqueio.

\section{Atuais enfrentamentos da Reforma Agrária no Território Rural do Bolsão/MS}

Como abordado anteriormente, a agricultura camponesa familiar depara-se com múltiplas dificuldades no Território Rural do Bolsão/MS, especialmente após a escolha deste como área prioritária para o monocultivo de eucalipto. Essas dificuldades são ocasionadas pela nova reconcentração fundiária derivada do avanço do monocultivo do eucalipto sobre terras que poderiam ser direcionadas para a política de reforma agrária.

Além disso, conforme observado em saídas de campo destacamos o grave estado de abandono desses projetos de assentamentos por parte do Estado, em que a maioria das famílias assentadas ainda vivem em condições muito precárias de moradia; com dificuldades na produção por causa da baixa fertilidade do solo decorrente da criação de gado realizada anteriormente; principais estradas que ligam assentamento aos municípios 
vizinhos não possuem pavimentação, o que dificulta a comercialização da produção; e para agravar a situação, as condições climáticas são caracterizadas por épocas prolongadas de seca.

Como exemplo, podemos destacar o projeto de assentamento Alecrim (figura 1), localizado no município de Selvíria à aproximadamente $45 \mathrm{~km}$ da sede municipal, que nos apontam desafios a serem enfrentados com o cerco deste pelo monocultivo do eucalipto e as péssimas condições de conservação da estrada (ainda sem pavimentação que liga o assentamento à cidade de Selvíria), impondo dificuldades a comercialização dos produtos. Vejamos o relato que evidencia esta situação:

[...] aqui deveria ser $5 \mathrm{~km}$, é $2 \mathrm{~km}, 10 \mathrm{~km}$ no máximo duma cidade, no máximo, no máximo, aonde eu poderia levar ai uns três, quatro cachos de banana vendia tirava a gasolina, ou comprava lá uns quilos de carne e trazia prá casa, outro dia eu ia na cidade comprava mais alguma, vendia banana, vendia alguma outra coisa, comprava outra coisa, mas $50 \mathrm{~km}$ da cidade não dá pra você, como é que você vai pegar dez frangos aqui [colocar] dentro do carro, dentro desses carros aqui você vai pagar 30 real pra ir na cidade e voltar, e o negócio que você foi vender vai te garantir os 30 real, mais a o seu dia de serviço e garantir talvez uma quebra do carro? Não dá isso nunca [...] os políticos só arruma a estrada com um mês, três meses antes deles sair para fazer campanha política (assentado do projeto Alecrim, 2013 - Selvíria/MS)

Figura 1: cerco do eucalipto e estradas de acesso ao município de Selvíria/MS - PA Alecrim
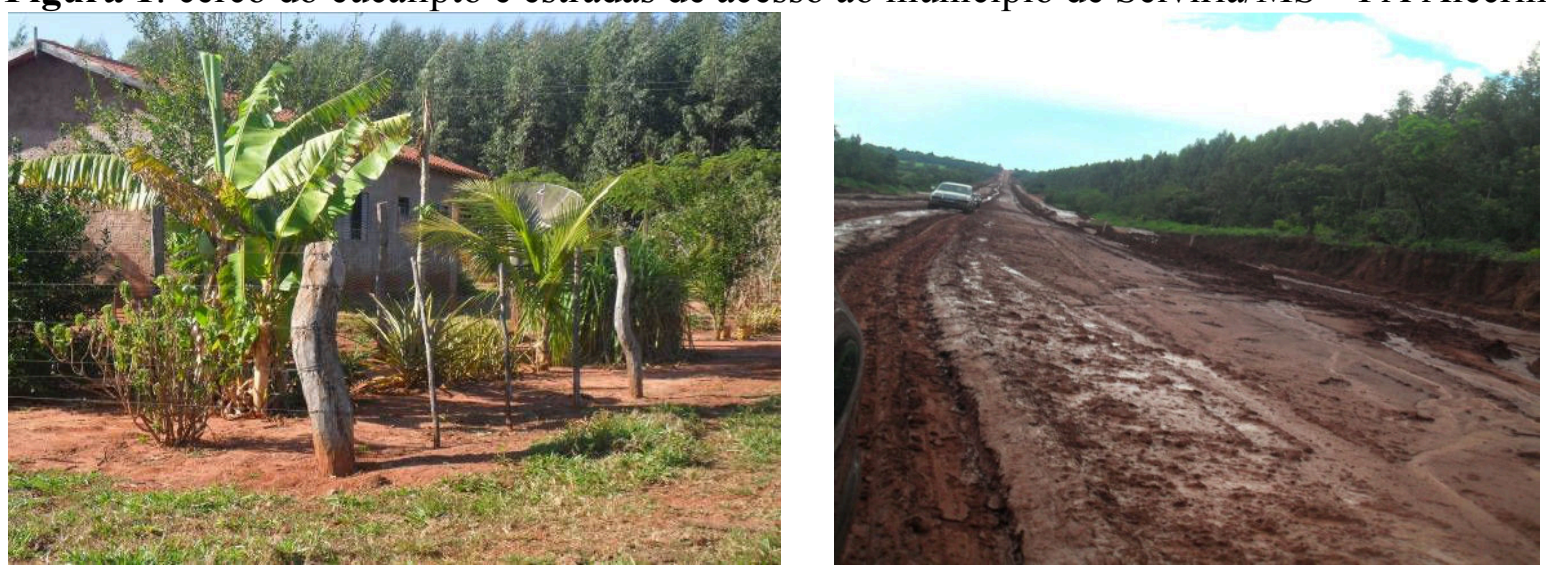

Fonte: Trabalho de campo, Novembro de 2013.

Organizado pela autora.

Outro exemplo é o projeto de assentamento São Joaquim (figura 2), implantado no ano de 2008, contemplou 181 famílias, localizado a cerca de $80 \mathrm{~km}$ da sede do município de Selvíria, às margens da rodovia MS-112, que faz a ligação da cidade de Três Lagoas - Inocência, e às margens da rodovia MS-444, trecho de Selvíria - Inocência. 
Nele, a maioria das famílias assentadas, até o momento de realização da pesquisa ainda viviam em condições precárias de moradia, e com a ausência do estado e de apoio técnico.

[...] ah, eu acho que tá muito atrasado, acho que o governo, o INCRA, deveria olhar mais pro pessoal aqui, só enterrou o pessoal aqui e até agora, condições nada. Por exemplo, a gente já está com três anos sem as casas, ainda bem que tem a água né, mas sem a luz, eu acho que, sem a água e sem a luz, é quase impossível de viver porque se a gente tiver um projeto na cabeça, mas se não tem a água e não tem a luz, não teria como sobreviver no lugar desse. A gente tá aqui, porque a gente é herói sabe, a gente quer a terra, se não fosse as firmas eu não sei por que a cesta [básica] que vinha até um determinado tempo, cortou. O INCRA mandava a cesta todo mês e ai foi cortado a cesta, e ai eles fala que depois de 12 meses que tem o sorteio da terra, não vem mais cestas, até então cada um luta do jeito que pode, um tira um leitinho, faz um queijo, vende; outro, vende um frango; outro o mel, que é o meu caso, né? E ai é assim [...]. Então eu acho que o governo federal deveria olhar mais por esse povo que tá [no assentamento], eu acho que deveria não dar mais terra pro povo, agora nesse momento, eu acho que deveria alicerçar o povo (...) que já tá na terra [...]. (Assentado do Projeto São Joaquim, 09/12 - Selvíria/MS. Grifo nosso) $)^{2}$.

Figura 2: condições de moradia no PA São Joaquim - Selvíria/MS.
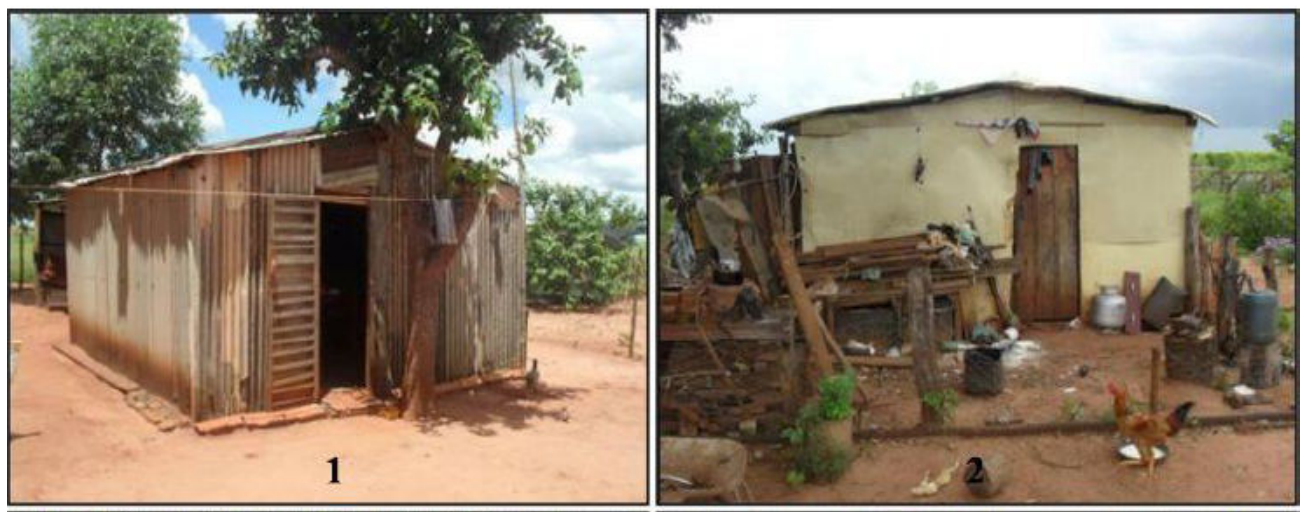

Fonte: Fonseca, 2014.

No município de Três Lagoas, temos o caso do projeto de assentamento 20 de Março, onde as dificuldades estão relacionadas com a baixa fertilidade do solo para produção alimentar, ausência de apoio técnico, inviabilidade de comercialização. Dentre as mais sentidas pelos assentados, também está a questão da falta de luz elétrica, assim como no PA São Joaquim:

[...] a turma do Incra, essas pessoas que vem cortar a terra não sabe avaliar terra pra pobre não, porque isso daqui não é terra pra pobre trabalhar não [...] que nem essa horta ai oh! Eu funcionei melhor que todos porque eu já cheguei com uma carga, com uma bagagem, porque se eu tivesse sem bagagem, eu estaria igual os outros ou pió [...] (Assentado do projeto Vinte de Março, 2013 - Três Lagoas/MS) 
Mesmo diante de tantas dificuldades, no decorrer da pesquisa identificamos diversas maneiras inovadoras encontradas pelos assentados para permanecer na terra. Situação que nos evidenciaram que o (re) criar camponês não está guiado apenas pelo acesso à terra, mas também pela busca incessante de nela permanecer e do seu reconhecimento de produtor de alimentos perante a sociedade.

Nos assentamentos de Selvíria e Três Lagoas, municípios pertencentes ao Território Rural do Bolsão/MS foi possível verificar algumas formas de resistência ora conformada, ora emancipatória. Considerando a primeira como forma contraditória de resistência, dependente de organização externa ao assentamento, como exemplo os projetos sociais e o vínculo empregatício relacionados com as indústrias de celulose e papel: Fibria e Eldorado. Já a emancipatória, é aquela conduzida por organização interna, ou seja, conquistada pelos assentados, como o Programa de Aquisição de Alimentos PAA e Programa Nacional de Alimentação Escolar PNAE. Observações apresentadas a seguir.

\section{Caminhos contraditórios da resistência}

No caso da resistência conformada via vínculo empregatício podemos considerar o caso dos assentamentos Alecrim e São Joaquim - Selvíria/MS, onde aproximadamente 40 assentados, entre eles adultos e adolescentes, homens e mulheres, trabalham com carteira de trabalho assinada nas indústrias: Eldorado, JS, Plantar, Fibria, exercendo atividades diversas, desde o plantio de mudas até como encarregados.

[...] a maioria do pessoal aqui até então, vive assim trabalhando na firma [...] do eucalipto. É uma firma do eucalipto, em parceria com a Eldorado, é uma terceirizada. Tem três ônibus que circula aqui dentro que leva o pessoal cedo, e traz praticamente quase às 10 horas da noite [22h] pra cá (...). (Assentado do Projeto São Joaquim, 2012 Selvíria/MS. Grifo Nosso).

Salientamos que a nossa proposta de análise não é julgar, muito menos denunciar os vínculos empregatícios dos camponeses com as indústrias, mas entender o significado para a reprodução camponesa do trabalho fora do sítio. Isto porque, a nosso ver, as condições que facilitaram a arregimentação da mão de obra dos assentados por parte das indústrias foi justamente o estado de abandono que esses projetos se encontram atualmente. Assim, a luta histórica pela conquista da terra como lugar da autonomia camponesa é de certa forma postergada porque as famílias para não abandonarem os sítios 
se veem na condição de trabalhar fora dele. Selecionamos a fala deste assentado por entendermos que ela é muito esclarecedora em relação ao que acabamos de interpretar.

Quando eu vim pra cá, eu não tinha serviço, eu não tinha nada, tinha que arrumar um serviço! Primeiro serviço que apareceu: Eldorado, fui trabalhar lá. Isso não era nem Eldorado na época, era Florestal Brasil, ai comecei a trabalhar lá, fiquei lá até dezembro, entrei em julho e fui até dezembro. Ai mudou o nome da empresa, saiu Florestal e entrou Eldorado, e eu continuei na empresa. Acho que foi em 2011 que eu entrei [...] Aqui na época não tinha condições de viver aqui dentro, ou você trabalhava pra fora, ou você saia do assentamento. Aqui não tinha opção pra nada, quando cheguei aqui. Aqui era um lugar pra se morar [...] (Assentado do projeto São Joaquim, 2014 - Selvíria/MS)

Alguns autores explicam o trabalho acessório (atividade assalariada fora da propriedade familiar), como forma de resistência camponesa nos momentos de crise econômica provocadas pelas épocas de seca ou de baixa produção. Para Almeida; Tomiasi (2010, p. 21):

[...] é precisamente o fato de não visar o lucro de sua atividade econômica, mas a reprodução do grupo familiar, mesmo quando é dono da propriedade jurídica da terra, que permite respostas adaptativas às crises, recorrendo até mesmo ao trabalho acessório não agrícola e à migração $[\ldots]$

Dois elementos de análise são essenciais para a compreensão desta realidade camponesa, até certo ponto contraditória. O primeiro é que o camponês não rompe com as atividades de produção no sítio, elas apenas são realizadas por outros membros da família, ou por ele mesmo, nos intervalos de folga do trabalho, em especial nos finais de semana.

Essa relação é típica em ambos os assentamentos estudados. Muitos, daqueles que, durante a semana, estavam na lida dos plantios de eucalipto, nos finais de semana dedicavam-se a atividades de produção no sítio, entre as quais o trabalho com a horta, o mutirão para conserto de cercas ou ampliação das casas. Condição bem enfatizada por Shanin (2008, p. 27):

A economia Familiar tem seus próprios modelos, suas próprias estruturas e seu próprio significado primordial que não desaparece. Por isso, sob certas condições, a economia camponesa é mais eficiente do que economias não camponesas. Os membros da família e o modelo familiar básico de bem-estar econômico estão envolvidos de forma particular num sistema de uso do trabalho que não é trabalho assalariado, mas trabalho familiar. Daí a sua capacidade para resolver problemas que outros tipos de economia não resolveriam de uma maneira tão eficaz e pouco dispendiosa. 
Outro elemento que indica a transitoriedade dessa situação é que, ao adquirir equilíbrio na situação financeira da família ou com a chegada da época das chuvas, o camponês assentado rompe o seu vínculo empregatício e volta a dedicar-se, em tempo integral, às atividades do sítio. Situação muito frequente nos projetos de assentamento estudados: algumas famílias já saíram do emprego e agora estão apenas cuidando do sítio, como é o caso de um assentado do PA Alecrim, que ao perceber que estava abandonando e prejudicando as atividades do sítio, preferiu sair da indústria:

O sonho era plantar e conseguir tirar o sustento daqui de dentro da terra, [...] trabalhava que néh doido ai, e vai, vai, vai, daqui um pouco estava passando até necessidade, ai fui trabalhar numa empresa, na época era Florestal Brasil, ela mudou a fantasia agora é Eldorado, saia daqui cinco hora da manhã, chegava aqui oito, nove hora da noite, ai se já viu, o que eu tava fazendo aqui no sitio, só vinha dormir [...] entojei, entojei mesmo, teve um ano que trabalhando nessa empresa eu perdi quatro vacas atolada, ai fui fazer umas contas na época valia mil e quinhentos cada vaca, que até hoje não subiu quase nada, perdi seis cruzeiro [reais] ai fui fazer a conta, eu perdi seis meses de emprego, vou ter que trabalhar seis meses agora pra mim recuperar o prejuízo que eu tomei, porque se eu tivesse lá essas vacas não tinham morrido, entendeu? Ai eu sai $[. .$.$] eu vou achar um jeito de ganhar dinheiro nesse negócio aqui$ [sítio], eu vou achar um jeito, com o [sítio], tem que viver, tem que viver com isso daqui! Se a foia [hortaliças] não deu, mas o milho tem que dar, se o milho não deu a abobora tem que dar [...] porque você não pode mexer com uma cultura só, você tem que mexer com várias culturas, porque se naquele ano a hora que você ter que vender ta ruim, tem aquela outra que esta te acudindo [...] (Assentado do projeto Alecrim, 2014 - Selvíria/MS)

Com esse relato podemos identificar a diferença do sentido da terra para os camponeses e para os capitalistas. A terra, para estes é meio de acumulação de renda e extração de mais valia pela exploração do trabalho, advinda de relações especificamente capitalistas, para aqueles, conforme analisa Balduíno (2004) a terra é lugar da moradia e do trabalho familiar, fonte de vida ou de existência.

Seguindo na perspectiva de explicitar e/ou compreender melhor as formas de resistência conformada vivenciadas pelos camponeses assentados, a seguir abordaremos os programas sociais das indústrias de celulose e papel, a saber: Fibria e Eldorado Brasil. Estes além de serem desenvolvidos nos PAs do município de Selvíria, também estão presentes nos PAs do município de Três Lagoas. 
Ressaltamos, porém, que o objetivo central desses programas sociais está relacionado especialmente as atividades produtivas, já a comercialização fica de responsabilidade dos assentados, momento em que as indústrias garantem apenas aporte técnico jurídico.

Para Kudlavizc; Almeida (2014, p. 3) a implantação de programas sociais das indústrias nos assentamentos e os atuais enfrentamentos da reforma agrária têm colaborado para o que os autores denominam de "privatização da reforma agrária". Essa privatização é caracterizada pelo conjunto de ações e programas sociais desenvolvidos pelas indústrias de celulose e papel nos projetos de assentamento, especialmente para a obtenção de certificações para a venda da produção. Assim, são:

Práticas empresariais que devem ser entendidas num contexto específico, qual seja o de que as empresas receberam volumosos incentivos fiscais (e ambientais) para se estabelecerem na região e que devem conduzi-los em forma de "desenvolvimento sustentável" - leiase restituir parte destes benefícios em favor da comunidade local na forma de projetos sociais. A isso se mescla a necessidade de adquirirem o selo de origem que funciona como sinal aos consumidores globalizados que o produto, ou seu componente, é proveniente de uma floresta que não impactou seu entorno, em outras palavras: ambientalmente adequado, economicamente viável e socialmente justo.

Entre as parcerias das papeleiras com os PAs temos o programa das hortas de Produção Agroecológica Integrada Sustentável - PAIS (Eldorado Brasil juntamente com o SEBRAE) e Programa de Desenvolvimento Rural e Territorial - PDRT (Fibria juntamente com as prefeituras, instituições e representantes da sociedade civil).

O programa PAIS está ligado a uma tecnologia social que aborda nova alternativa de trabalho e renda para agricultura familiar, estimulando um cultivo diversificado e agroecológico. Conforme se lê no Manual:

O projeto PAIS - Produção Agroecológica Integrada e Sustentável [...] É abordado um antigo conceito no modo de ver o mundo, interagindo com o meio ambiente e com a sociedade. Contrariando a diversos paradigmas agrícolas: a simples produção agrícola de "commodities", a dependência de inseticidas, pesticidas, fertilizantes e outros produtos químicos para obtenção de alimento, uma agricultura onde a larga escala de produção é fator primordial de sucesso e rentabilidade [...]. (MANUAL PAIS, 2012, p.4. Grifo do autor) 
A respeito da produção agroecológica, Guzmán; Molina (2005) enfatizam que ela é a única solução possível para se pensar a diminuição dos problemas ambientais do tempo presente, derivado da apropriação capitalista da natureza. Este modo de produzir não está relacionado apenas ao manejo ecológico dos recursos naturais, mas também à conscientização social e política em relação a soberania alimentar no campo e na cidade. Para os autores, a eficácia do caminho agroecológico depende de uma agricultura sustentável que vise à autonomia dos sujeitos, que, por sua vez, esta intimamente ligada ao modo de vida camponês.

Segundo informações obtidas a partir das entrevistas a campo com os assentados do PA Alecrim, São Joaquim e Pontal do Faia, envolvidos no programa PAIS (figura 3), inicialmente a implantação do programa permitiu que os assentados idealizassem melhorias na condição de vida, ao ponto de terem produção suficiente para auferirem renda e manterem-se no sítio. Por conta disso, antes mesmo do início do programa, algumas famílias romperam com os vínculos empregatícios nas indústrias de eucalipto.

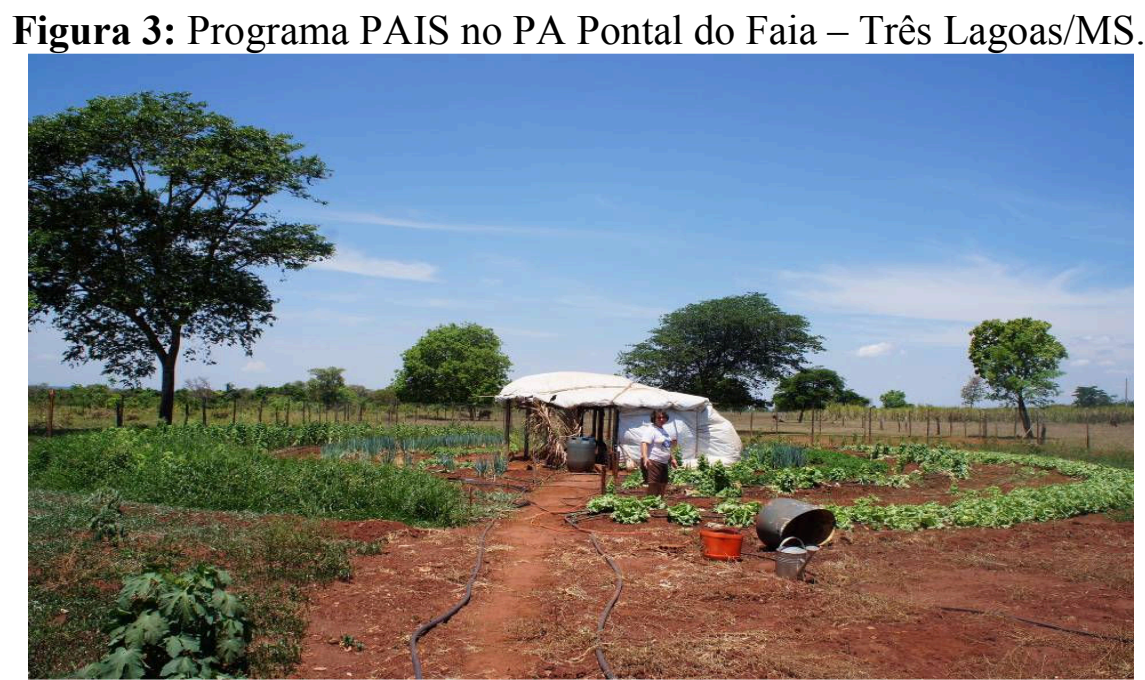

Fonte: Trabalho de Campo 2013/2014. Organizado pela autora.

Porém, no desenrolar do programa, dificuldades apareceram, especialmente em relação a desorganização da distribuição dos materiais para a montagem da horta de responsabilidade da empresa. Situação vivenciada em ambos os projetos de assentamentos, contribuindo em alguns casos no prejuízo financeiro, pois cansados de esperar os equipamentos que faltavam, as famílias prepararam a terra, compraram parte 
dos materiais por conta própria, e deram início ao projeto (figura 4) sem auxílio, como enfatiza o relato que segue:

[...] a horta tá produzindo só que por conta nossa [...] desde o mês de junho que esse projeto, eles vieram aqui e puseram esse projeto tudinho ai, daí eles disseram assim que oia!, falou quem tinha ganhando néh! Quem tinha sorteado pra poder pegar, porque só [teria] treze [kit] aqui dentro né, ai nóis já pegamos ali, porque essa parte que nóis montemos essa horta era cana que a gente tinha lá, ai a gente já pegamos um trator já gradeamos lá, e já comecemos plantar lá porque disse que era logo, que era logo néh! E por fim da conta até hoje [novembro] e vai fazer curso, e faz curso, e faz curso e até agora nada de desenrolar. Eu vou falar: porque eu não sei não se for pro ano que vem, a gente vai acabar desistindo também porque, já desistiram bastante hein! [...] porque isso daí que é ruim, já gastamos, já compramos tela pra gente cercar aquilo ali [o espaço para a horta] aqui as casas são muito perto então como a gente vai plantar uma horta se você não cercar? [...] então nóis já compremo isso daí, então vamo adiantar, porque eles chegando e vendo que a gente táh com interesse néh! Eles entregam o material, mas até hoje [...] (Assentada 01 do projeto Alecrim, 2013 - Selvíria/MS).

Figura 4: hortas do PAIS semiestruturadas pelos assentados do PA Alecrim e São
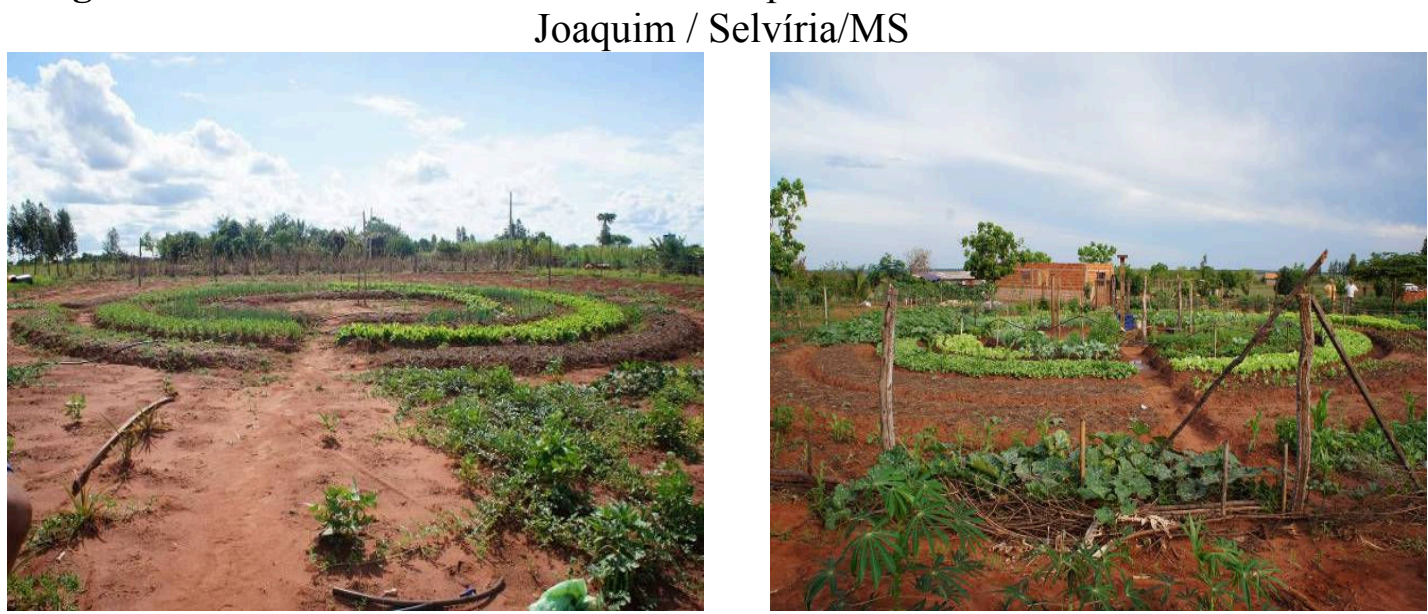

Fonte: Trabalho de Campo 2013/2014.

Organizado pela autora.

Outra situação observada foi à alto índice de desistência do programa e a retomada ou continuidade do vínculo empregatício com indústrias de eucalipto, como podemos ver no relato que segue:

[...] não entregaram o kit ainda, eu acho que é esse um ponto que as pessoas desanima, porque o projeto é pra ontem, entendeu, o povo daqui já tá necessitado de trabalhar, porque se tá na cidade, esta sem serviço, aqui você tem muita gente que trabalha em firma, mas o projeto, o plano de vim pra cá não é trabalhar em firma, a gente veio pra trabalhar na roça se fosse pra todo mundo vir e ficar envolvido em serviço deixava a fazenda pro fazendeiro, no meu pensamento ai se vê que esse projeto ai eles faz esse projeto e tal, ai demora pra ser executado o pessoal não 
tem saída tem que ir pra firma [...] (Assentada 02 do projeto Alecrim, 2013 - Selvíria/MS)

O Programa PDRT foi responsável por desenvolver projetos nos municípios de Brasilândia, Três Lagoas e Selvíria, que segundo o site de assessoria da Fibria, Painel Florestal, tem o objetivo de fortalecer as cadeias produtivas das comunidades rurais via capacitação das associações nas linhas de gestão, produção e comercialização.

No município de Três Lagoas, destacamos as hortas tradicionais implantadas no projeto de assentamento Vinte de Março (figura 5), localizado na BR 262 (sentido Três Lagoas - Água Clara), criado no ano de 2009, no município de Três Lagoas, beneficiando 69 famílias. Nele, assim como nos projetos de assentamento do município de Selvíria, também havia certo número de assentados com vinculo empregatício com a indústria de eucalipto, no caso a Fibria.

Figura 5: programa das hortas convencionais no assentamento Vinte de Março - Três Lagoas/MS

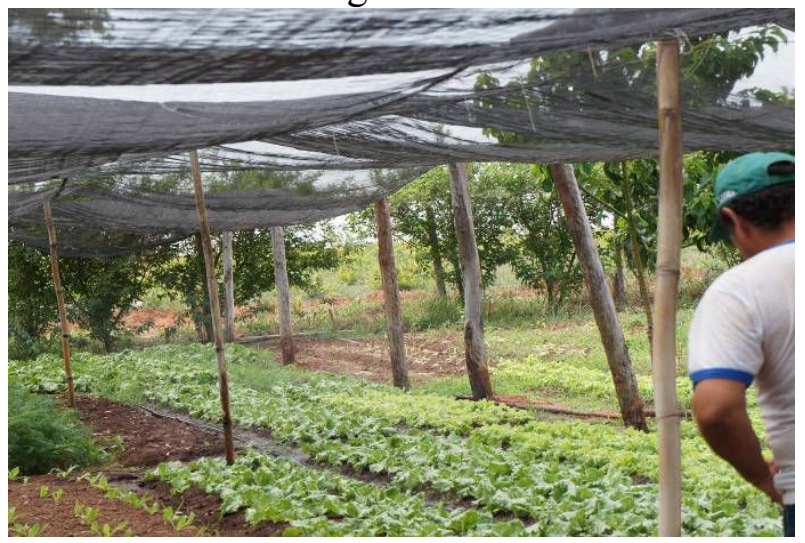

Fonte: Trabalho de Campo 2013/2014. Organizado pela autora.

No início do projeto, muitos assentados perderam grande parte da sua produção, porque ainda não tinham a liberação da Declaração de Aptidão ao Pronaf (DAP), condição essencial para conseguirem entregar a produção para os programas das cotas estatais, como é relatada pela assentada no decorrer da entrevista:

[...] eu no meu caso, eu falei pra eles: que o que eu não vendi na época que não tinha vendas eu joguei tudo pros porcos. Assim, joguei tudo não, joguei muito, comi bastante, dei bastante verdura, e a maioria que não vendemos demos pros porcos [...] porque não tinha DAP, o INCRA, 
O paradoxo destas ações das industrias de celulose e papel, qual seja: implantar programas sociais nos projetos de assentamento tem explicação no fato de que as indústrias envolvidas com atividades de exportação de celulose necessitam de ações sociais para garantir os selos de certificação, exigência fundamental para a venda do produto nos mercados europeus.

Em avaliação do papel das indústrias na permanência (ou não) dos camponeses no chão de reforma agrária concluímos que mesmo diante de tantas dificuldades na efetivação dos programas, o mecanismo de criação de associações possibilitou aos assentados a organização necessária para comercializar a produção aos mercados institucionais (PAA e PNAE) nos níveis da prefeitura, estado e governo federal.

A organização em associações e participação efetiva no PAA e PNAE as famílias conseguiram adquirir renda extra mensalmente. O que analisamos ser a resistência baseada no princípio de emancipação.

\section{Os contornos em prol da emancipação}

O motivo de considerarmos como resistência emancipatória a apropriação dos canais curtos de comercialização pelas associações de assentados é que mesmo constando no esboço dos programas, ações relacionadas ao fortalecimento produtivo e comercialização, na prática eles desenvolveram apenas a escala produtiva das famílias, e as conquistas dos canais de comercialização advinha da própria capacidade do grupo de recriar enquanto agricultores de alimentos.

No assentamento Pontal do Faia - Três Lagoas/MS, das nove famílias contempladas com os kits do programa PAIS, três conseguiram, no ano de 2014, entregar os produtos da horta orgânica para a merenda escolar (PNAE), em especial as hortaliças e legumes. Só no primeiro semestre, eles atenderam 13 centros de educação infantil, 2 creches, 1 centro educacional e 1 igreja, totalizando 17 instituições atendidas, contemplando aproximadamente 3.400 beneficiários, conforme o quadro 1 : 
Os contornos da resistência: agricultura camponesa

Mariele de Oliveira Silva familiar no limite da expansão do monocultivo de eucalipto no Território Rural do Bolsão/MS

Quadro 1: CEIs e quantidade de alunos atendidos pela Associação do PA Pontal do Faia

\begin{tabular}{|l|l|}
\hline CEIS & Alunos Atendidos (2013) \\
\hline Creche Dona Clementina Carrato & 90 \\
\hline Centro Educacional ProfäMaria Aparecida do Nascimento Castro & Capacidade 425 \\
\hline Centro de Educação Infantil Diva Garcia de Souza & 102 \\
\hline Centro de Educação Infantil Diógenes de Lima & 259 \\
\hline Centro de Educação Infantil Guanabara & 281 \\
\hline Creche Irmã Sheila & 245 \\
\hline Centro de Educação Infantil Jaci Cambuí Ferreira & 206 \\
\hline Centro de Educação Infantil Jupiá & 97 \\
\hline Centro de Educação Infantil Lilian Márcia Dias & 136 \\
\hline Centro de Educação Infantil Massumi Otsubo & 171 \\
\hline Centro de Educação Infantil Novo Alvorada & 262 \\
\hline Centro de Educação Infantil Nilza Tebet Thomé & 175 \\
\hline Centro de Educação Infantil Neide De Souza Lima & Capacidade 250 \\
\hline Centro de Educação Infantil Nossa Senhora Aparecida & 300 \\
\hline Centro de Educação Infantil Olga Salati Marcondes & 214 \\
\hline Centro de Educação Infantil Santa Luzia & 143 \\
\hline Igreja Nazareno & Não informado \\
\hline
\end{tabular}

Fonte: Cronograma de distribuição, Pontal do Faia. Organizado pela autora.

Além disso, alguns integrantes do grupo também comercializavam sua produção no assentamento e participavam da feira local da cidade de Três Lagoas aos sábados (figura 6); e outros entregavam de porta em porta nas casas e restaurantes.

Figura 6: comercialização dos produtos do programa PAIS na feira local de Três

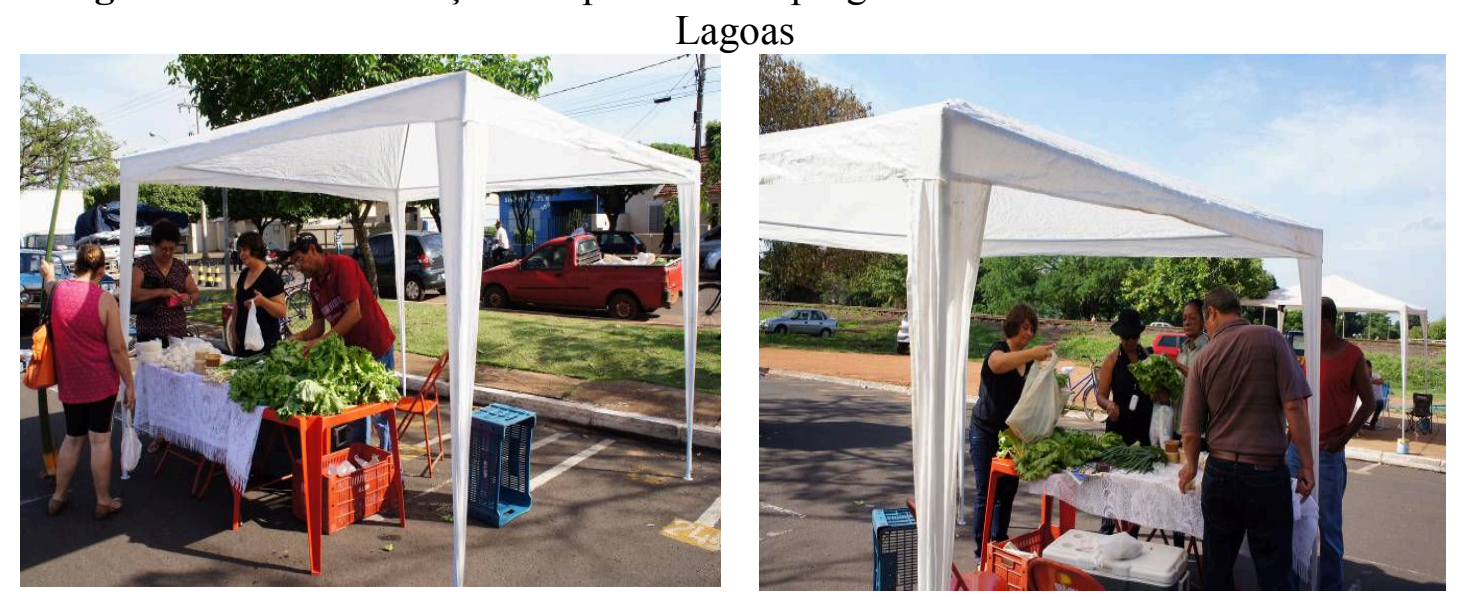

Fonte: Trabalho de campo, 2013.

Organizado pela autora.

À semelhança do que ocorreu no Pontal do Faia, os assentados do PA Vinte de Março, após a liberação da DAP, algumas famílias conseguem comercializar na feira 
(figura 7 - A) e assentamento. Como a produção na horta era maior que a demanda, e no intuito de diminuir o desperdício das verduras, buscaram, via Associação, caminhos para o escoamento da produção, momento em que 19 das 34 famílias participantes da associação comercializam seus produtos os mercados institucionais PAA e PNAE (figura 7 - B).

Figura 7: comercialização dos produtos do PA Vinte de Março - Três Lagoas/MS
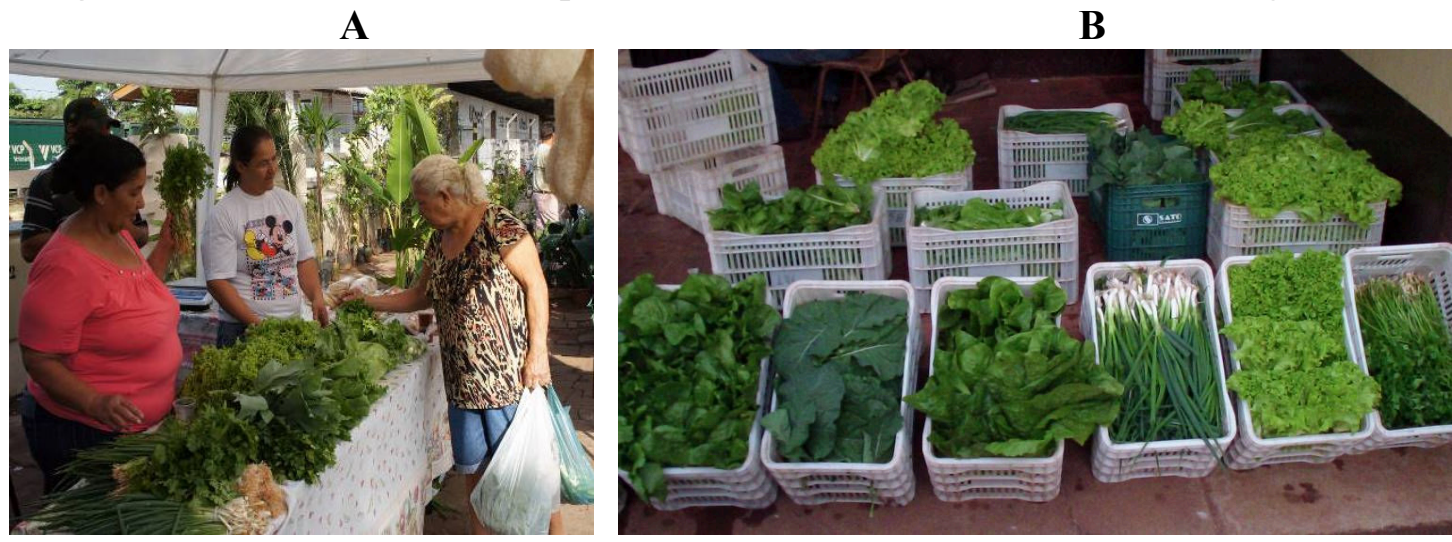

Fonte: Trabalho de campo, 2013.

Organizado pela autora.

Durante as entrevistas nos projetos de assentamento Alecrim e São Joaquim, pertencentes ao município de Selvíria, os assentados relataram que ainda não haviam conquistado os canais de comercialização e, produziam na horta apenas para consumo próprio. Entre as justificativas relatadas está a dificuldade de comercialização ocasionada pela distância que os assentamentos possuem em relação ao município de Selvíria, considerado o ponto mais próximo para comercialização, sendo $45 \mathrm{~km}$ (Alecrim Selvíria) e 80 km (São Joaquim - Selvíria).

Porém, em relação aos outros assentamentos aqui apresentados: Pontal do Faia e Vinte de Março, localizados no município de Três Lagoas não há dúvidas que a entrega da produção para o PAA e PNAE foi considerada positiva pelas famílias, em especial, porque boa parte da produção das hortas estava garantida para venda, contribuindo para a geração de renda e manutenção dos grupos familiares, fundamentais para a sua permanência no assentamento, evidente no relato a seguir:

No começo a gente achava muito barato, mas ai a gente foi fazer umas contas, a gente esta entregando aqui, a gente não esta tendo trabalho nenhum, não esta tendo perca nenhuma [...] então é mais negócio você 
vender pra Conab néh! Que vem buscar na porta você não tem que pagar esse frete pra levar lá na feira, você não tem que pagar o ponto na feira, e nem o ponto pra prefeitura [além disso] eu falo que foi o pessoal continuar nos projetos das hortas néh! Que tinha muitas pessoas que estavam pensando já em desistir, entregar a horta, porque não estava tendo venda pra tudo aquilo de produto, se não vem esse projeto de entregar pra Conab ninguém ia produzir na horta, por que produzir pra dar pra bicho? (Assentada 01 do projeto Vinte de Março, 2013 - Três Lagoas/MS).

\section{CONSIDERAÇÕES FINAIS}

No decorrer desta pesquisa observamos que uma das alternativas buscadas pelos camponeses na luta para ficar na terra, num cenário de deficiência das políticas públicas do Estado no tocante a reforma agrária, tem sido o trabalho acessório nas indústrias da agricultura capitalista, como é o caso dos assentados do projeto Alecrim, Pontal do Faia, São Joaquim e Vinte de Março. Porém, foi possível verificar, que quando lhes é dada a oportunidade de apropriação de políticas públicas que auxiliem na comercialização da produção desenvolvida no assentamento, como o PAA e o PNAE, eles retomam sua trajetória histórico de agricultores de alimentos de consumo popular e, portanto, de contribuição à soberania alimentar.

Acreditamos que, estas políticas públicas, contribuem, por um lado a superar as barreiras de mercado colocado pela lógica do sistema capitalista, e por outro, facilita a chegada dos produtos da agricultura familiar camponesa até os consumidores, principalmente aqueles que vivem em situações de extrema pobreza. O PAA e o PNAE além de tudo o que foi dito, também contribuem para valorizar a produção camponesa, voltado essencialmente para o consumo interno da população brasileira.

Confiamos que as vias de resistência encontradas atualmente pelos camponeses assentados não desqualifica os projetos de reforma agrária presentes nos municípios de Três Lagoas e Selvíria; antes, trazem à tona uma possível crise da Reforma Agrária como política pública, que ocorre do âmbito local para o global.

Assim, junto com o desenvolvimento do capitalismo, há novos processos de transformação na base de luta dos movimentos sociais camponeses. A dinâmica dos enfrentamentos não está pautada somente na terra que se manteve cativa, e por isso disputada pela classe dos capitalistas e dos camponeses, mas também na preservação da terra que foi conquistada. 
Notas

\footnotetext{
${ }^{1}$ Este artigo é parte da dissertação de Mestrado "A (re)criação do campesinato em Cáceres/MT e no contexto de expansão territorial do agronegócio em Três Lagoas e Selvíria em Mato Grosso do Sul".

${ }^{2}$ Transcrição de parte do relato do assentado referente aos projetos de reforma agrária - Selvíria/MS. Entrevista. Trabalho de campo realizada em Setembro de 2012 no projeto de assentamento São Joaquim.
}

\section{REFERÊNCIAS}

ALMEIDA, Rosemeire A. A questão agrária na contemporaneidade e os desafios do movimento camponês no Brasil. Montevidéu: Egal, 2009. (Mimeografado).

ALMEIDA, Rosemeire Aparecida de. (Org.). A Questão Agrária em Mato Grosso do Sul: uma visão multidisciplinar. Campo Grande: Ed. UFMS, 2008.

BALDUÍNO, Dom Tomás. Território de Vida, de luta e de construção da Justiça Social. In: OLIVEIRA, Ariovaldo U. (org.). O Campo no Século XXI. São Paulo: Editora Casa Amarela e Editora Paz e Terra, 2004.

Fibria apresenta investimento social para Três Lagoas-MS e região em 2013. Disponível em: < http://www.painelflorestal.com.br/noticias/celulose-e-papel/fibriaapresenta-investimento-social-para-tres-lagoas-ms-e-regiao-em-2013>. Acesso em: 05 de Agosto de 2013.

FONSECA, Silas Rafael da. Monocultivo de eucalipto, relações de trabalho e os caminhos da resistência camponesa no assentamento São Joaquim (MS). 2014. 149 f. Dissertação (Mestre em Geografia). Programa de Pós Graduação- Mestrado em Geografia da Universidade Federal da Grande Dourados. Dourados. 2014.

GUZMÁN, Eduardo Sevilla; MOLINA, Manuel González. Sobre a evolução do conceito de campesinato. Tradução literal [de] Ênio Guterres e Horacio Martins de Carvalho. São Paulo: Expressão Popular, 2005.

KUDLAVIZC, Mieceslau; ALMEIDA, Rosemeire Aparecida de. Em tempos de "privatização" da reforma agrária, a necessária práxis do bem comum. BOLETIM DATALUTA, Artigo do mês de: fevereiro de 2014. Disponível em: $<$ http://www2.fct.unesp.br/nera/artigodomes/2artigodomes_2014.pdf/>. Acesso em: 25 de Maio de 2014.

PAIS beneficiará mais 25 famílias de Três Lagoas. Disponível em: $<$ http://www.cultura106fm.com.br/noticias/view/?id=6127/>. Acesso em: 05 de Agosto de 2013.

PAULINO, Eliane Tomiasi; ALMEIDA, Rosemeire Aparecida. Terra e Território: a questão camponesa no capitalismo. São Paulo: Expressão Popular, 2010. 
Crase Coração de Mãe comemora quatro anos em Três Lagoas. Disponível em: $<$ http://www.bolsaoms.com.br/noticias/tres_lagoas/crase_coracao_de_mae_comemora quatro_anos_em_tres_lagoas/>. Acesso em: 05 de Junho de 2014.

Painel Florestal. Disponível em: <http:/www.painelflorestal.com.br/noticias/celulosee-papel/fibria-apresenta-investimento-social-para-tres-lagoas-ms-e-regiao-em-2013/>. Acesso em: 10 de Novembro de 2013.

Prefeita empossa diretores de Escolas Municipais e CEI's. Disponível em: $<$ http://www.treslagoas.ms.gov.br/noticia/prefeita-empossa-diretores-de-escolasmunicipais-e-cei-s/7318/>. Acesso em: 05 de Junho de 2014.

SHANIN, Teodor. Lições Camponesas. In: PAULINO, Eliane Tomiasi; FABRINI, João Edmilson (Orgs). Campesinato e territórios em disputa. São Paulo: Expressão Popular, 2008. 